\title{
The Human Body's Own Language to be Considered for Safe and Effective Neurostimulation
}

Metin Tulgar $\cdot$ Safiye Bilgin $\cdot$ Ayhan Yildirim

To view enhanced content go to www.neurologytherapy-open.com

Received: March 15, 2012 / Published online: June 9, 2012

(c) The Author(s) 2012. This article is published with open access at Springerlink.com

\section{ABSTRACT}

Introduction: The general objective of this study was to provide an improved software for safer and more effective neurostimulation therapy.

Materials and Methods: Tulgar implants, employing combined modulation of stimulation synchronized with heart rate, breathing frequency, and position of the patient (HBP), were applied as vagus nerve stimulation (VNS) for the management of refractory epilepsy in 105 patients who were followed up for 1 year.

M. Tulgar ( $\bowtie)$

Neurotechnology Research Center, Alanaldi Cd.

Didem Sk. 7/1 D.7 İcerenkoy, Atasehir, 34752 Istanbul, Turkey

e-mail: metintulgar@yahoo.com

\section{S. Bilgin}

Neurology Clinic, Hisar Hospital, Umraniye, Istanbul, Turkey

A. Yildirim

Neurosurgery Clinic, Yasam Hospital, Bahcelievler, Istanbul, Turkey

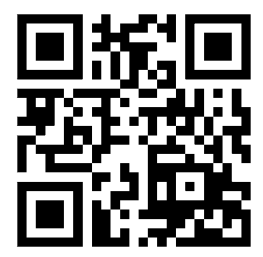

Enhanced content for this article is

available on the journal web site:

www.neurologytherapy-open.com
Results: Fifty-nine out of 105 (56.19\%) patients were seizure free, $34(32.38 \%)$ patients had partial improvement in quality of life with a decrease in intensity and frequency of the seizures, and 12 (11.43\%) patients did not respond to stimulation.

Discussion: Other similar studies, undertaken with non-Tulgar equipment, reported a $10 \%$ full recovery, $60 \%$ partial improvement in quality of life, and 30\% zero response. Comparisons of these results reveal an approximate fivefold increase in seizure freedom, and threefold decrease in the number of nonresponsive patients.

Conclusions: The findings of the present study imply that HBP-modulated mode of stimulation could be safer and more effective in neurostimulation, at least in VNS.

Keywords: Epilepsy; Heart, breath and position mode of stimulation; Neurostimulation; Quality of life; Seizures; Tulgar implants; Vagus nerve stimulation

\section{INTRODUCTION}

Neuroimplant is a clinical tool that stimulates the nervous system under the skin following surgery [1]. 
Neurostimulation is a process by which nerves partially losing their function as a result of disease or trauma are stimulated using artificial electrical pulses for regeneration [2]. Electrical signals used for this purpose must be consistent with the nature of human neurophysiology [3]. Confusion resulting from chaos in electrical parameters may lead to misuse of otherwise clinically established neurostimulation therapy. Earlier studies have shown that certain selected parameters play an important role in the safety and efficacy of the therapy for various applications [4-15]. Whilst comprehensively considering scientific aspects of stimulation, the recently developed Tulgar neuroimplant system has made possible the opportunity to try parameters which are consistent with the nature of the human body [16-18]. This study is one of seven steps of a long-term research program related to Tulgar implants: (1) the development of a prototype model; (2) bench testing with the prototype; (3) laboratory tests; (4) environmental safety tests; (5) development of clinical model that is implantable in the living tissue; (6) animal testing [17]; and (7) pilot implantation in humans. The data presented in the present study covers the human implantation phase.

\section{MATERIALS AND METHODS}

\section{Patient Selection}

Since 2007, 105 patients (64 males and 41 females) suffering from refractory epilepsy for 3-35 years participated in the study. The patients were aged 5-69 years (mean 28.11 \pm 12.90). Eighteen patients were children ( 14 boys and 4 girls) aged 5-15 years (mean $10.22 \pm 3.28$ ). MATLAB 7.5 R2007b (The MathWorks Inc., Natick, MA, USA) was used for statistical procedure.
The subjects were experiencing two or more tonic chronic convulsions a week, in addition to four or more absence seizures a day despite use of four or more anti-epileptic drugs. One patient underwent failed resective epilepsy surgery before this study, with only a $10 \%$ benefit in terms of intensity and frequency. All other patients were not indicated for resective surgery. No patients with mental disorders participated in the study. None of the participants had brain tumors.

\section{Implants}

Tulgar implants were used after approval by the Ethical Committee of the Ministry of Health of the Republic of Turkey. Technical specifications of the implants are explained elsewhere [17]. The main goal of the Tulgar neuroimplant, which is a semi-implantable system, is that the implanted part is completely passive, containing neither a battery nor any active electronic components. This allows patients to use such a breakdownfree system for as long as they require it. There is no risk of extra surgery for replacement of the system that may result from electronic failure or a limited battery life. A finger-tip sized external compact stimulator powers and controls the system, and is placed on the skin overlying the implanted passive element. The external unit is recharged by a portable charger every 2 weeks. During recharging, patients can use the spare external unit provided. Programming of the external unit can easily be achieved using a purpose-built software located in a netbook. On the other hand, removal of the battery and active electronic components minimized the size of the passive element (79\% reduction in size), making it the smallest implant available at present. The reduction in size facilitates the surgery, 
particularly in children, and even in infants; however, infants must be 36 months old, following the advice of pediatric neurologists, so that the infant brain can complete its development [19].

\section{Implantation}

As with any vagal stimulation surgery, the left vagus nerve was exposed by removing the carotid sheet, and the nerve was separated below the superior and inferior cervical cardiac branches. A subcutaneous pocket below the clavicle bone in the left side of the chest was also created to house the passive element. The passive element in the chest pocket was secured with its silicone pad facing the skin, and by suturing three points at the edge of the silicone pad to the surrounding fascia. The electrode was subcutaneously tunneled through a guiding tube from the pocket to the neck. Once the tip of electrode reached the neck, the guiding tube was removed. The electrode was attached to the left vagus nerve by wrapping the electrode around the vagus nerve twice. A $2-3 \mathrm{~cm}$ length of electrode lead was allowed for strain relief in both incision sides. The incisions were then closed, with subcutaneous sutures being permanent and the remaining sutures cosmetic. Pre- and post-operative appropriate antibiotics were applied. Each surgery took approximately $1 \mathrm{~h}$ in addition to the anesthetic procedure. After hospitalization for one night, patients were sent home the following morning.

\section{Stimulation Parameters}

One of the main features of Tulgar implants is the application of stimulation in accordance with the human body's own language.
Employing Tulgar implants as vagus nerve stimulation (VNS), the authors modulated the stimulating signals whilst considering three factors: (1) heart rate; (2) breathing frequency; (3) position of the patient (HBP). Using these factors, a HBP mode of stimulation was applied. Physiological studies have shown that heart rate and breathing frequency change depending on age, sex, and position of the patient, e.g., standing up during daily life and lying down during sleep [19]. Having considered these physiological facts, the authors used eight age groups (4-11, 12-17, 18-25, 26-35, 36-45, $46-55,56-65,65+)$ for each sex, and for both positions. A netbook programmer operating with purpose-built software provided 32 options to be selected after clinical examination of each patient by the physician. A Tulgar TI1 Model VNS Implant System (manufactured in compliance with the Medical Device Directive [MDD] 93/42 European Economic Community [EEC] and Active Implantable MDD 90/385 EEC, under patent protection, and having full quality assurance certificates, namely CE, ISO 9001, and ISO 13485) generated $1 \mathrm{~min} \mathrm{ON}+2 \mathrm{~min}$ OFF therapeutic pulses which were compatible with cardiopulmonary activity. The other important point related to Tulgar implants is that a direct current-free signal is supplied. This eliminates undesirable electrolysis phenomena which may cause tissue necrosis [20].

\section{Follow-up}

Each patient was followed-up for 1 year. Stimulation started 2 weeks post-operation. Using the graphical interface program, the most suitable group of stimulation for each patient was applied. Patients were invited for control measurements in months $1,3,6$, and 12 
following neurostimulation. During the control measurements, the intensity and frequency of the seizures were recorded by means of visual analog scale (VAS) by a nurse who was blinded for the study program. The intensity of stimulation was increased by the programmer when necessary.

\section{RESULTS}

By the end of the 1-year follow-up period, 59 out of 105 (56.19\%) patients were seizure free, $34(32.38 \%)$ patients had partial improvement in quality of life with a decrease in frequency and intensity of the epileptic seizures, and 12 (11.43\%) patients did not respond to stimulation. One participant, an 18-year-old girl who underwent failed resective surgery before this study, which resulted in a benefit of only $10 \%$ in terms of intensity and frequency, reported a $70 \%$ improvement (reduction in frequency and intensity of the seizures). Among the children, 11 out of 18 $(61.11 \%)$ were seizure free and five $(27.78 \%)$ had partial improvement. Only two children (11.11\%) didn't respond to therapy. In adults, the seizures began to stop and participants experienced a full recovery as follows: 14 out of $59(23.73 \%)$ at the first control month, $17(28.81 \%)$ at the third month, 21 (35.59\%) at the sixth month, and seven $(11.86 \%)$ at the 12 th month. In children, participants reported full recovery as follows: three out of $11(27.27 \%)$ at the first control month, four $(36.36 \%)$ at the third month, two (18.18\%) at the sixth month, and two (18.18\%) at the 12 th month.

A total of 29 out of 105 (27.61\%) patients reported a reduction in the number of epileptic seizures during the resting period of 2 weeks following the operation and before the stimulation began.

\section{DISCUSSION}

Having compared the results of this study with the other similar studies undertaken with nonTulgar implants, there is a dramatic difference. Similar studies have reported only a $10 \%$ full recovery, $60 \%$ partial improvement in quality of life, and 30\% zero response $[21,22]$. Comparison of these results with those of the present study reveals an approximate fivefold increase in seizure freedom, and a threefold decrease in the number of nonresponsive patients.

There are two main differences between the Tulgar and non-Tulgar devices: (1) construction and (2) stimulation parameters. The Tulgar vagal stimulator is an externally powered and controlled, semi-implantable system with neither an implanted battery nor any active electronic components. In contrast, non-Tulgar devices are fully implantable systems. However, the difference in the construction cannot be the principle reason for the difference in results as both devices carry out the same function: management of refractory epilepsy. The real difference in study results derives from the stimulation parameters. Whilst non-Tulgar devices supply conventional stimulation in which pulses are repeated at a constant frequency, the Tulgar implant system applies completely different parameters which are consistent with the nature of human physiology. The authors can deduce that the only reason for the results to be different is the scientific algorithm of stimulation provided by Tulgar implants.

The present study addresses the question of whether it is really necessary to modulate the stimulation signals and, if so, how it is achieved? It is known that the brain demodulates the data from the peripheral nerve, detecting the patterns of nerve 
impulses, and paying particular attention to frequency $[23,24]$. Since the language that the brain understands is frequency, it might be worthwhile modifying the patterns of pulses rather than keeping them constant, i.e., the technique used in conventional mode of stimulation. Frequency modulation of the stimulus obviates, at least in part, this phenomenon, and delivers essential novel stimuli to which the nervous system responds without adaptation [25]. Considering the earlier scientific and clinical studies, the designing of patterns of electrical pulses is of particular importance. The human body is an integrated unitary system incorporating synchronized multifunctional sub-systems, with the nervous system coordinating this system. The language of the nervous system should be consistent with the other ongoing activities, such as cardiopulmonary activity. Furthermore, the body's own language also has to be considered when modulating the frequency, as modulation must be combined with other factors, such as heart rate and breathing frequency depending on age and sex, as well as the position of patient (standing up or lying down).

With regards to secondary outcomes, the reduction in epileptic seizures during postoperative resting time experienced by some participants might be explained by a mechanical stimulation effect resulting from the manipulation of the vagus nerve during surgery, and touching of the electrode to the neighboring tissue following surgery. Furthermore, another outcome of the present study is that, with these dramatic positive changes in the results in mind, improved VNS seems to be more cost-effective versus drug therapy for the management of refractory epilepsy [26].

The authors are, of course, aware that the alternative vagal stimulators have been studied in larger numbers of patients since 1997; however, the 105 patients included in the present study is not a neglectable population.

\section{CONCLUSION}

The findings of the present study imply that HBP-modulated mode of stimulation could be safer and more effective in neurostimulation, at least in VNS, and worth applying in extensive studies which include a larger number of patients.

\section{ACKNOWLEDGMENTS}

The authors' grateful thanks are due to Professor Giancarlo Barolat, Director of the Barolat Institute, Colorado, USA, for his kind consultancy. This study has been undertaken by the Neurotechnology Center, Istanbul, Turkey, without any grant. The project is already under patent protection (date of application: December 12, 2002) including in Turkey (TR 200501692 B approved on December 2, 2003) and the European Community (EU 1575665 approved on November 29, 2006). Since the first introduction, the project has continuously been improved, making the implantable parts smaller and magnetic resonance imagingcompatible. Also, a new fully implantable and externally-rechargeable (only one night a year) model has recently been developed under the same patent protection. Dr. Tulgar is the guarantor for this article, and takes responsibility for the integrity of the work as a whole.

Conflict of interest. The authors declare no conflicts of interest. 
Open Access. This article is distributed under the terms of the Creative Commons Attribution Noncommercial License which permits any noncommercial use, distribution, and reproduction in any medium, provided the original author(s) and source are credited.

\section{REFERENCES}

1. Miles JB, Lipton S, Hayward M, Bowsher D, Mumford J, Molony V. Pain relief by implanted electrical stimulators. Lancet. 1974;1:777-9.

2. Miles JB. Electrical stimulation for the relief of pain. Ann R Coll Surg Engl. 1984;66:108-2.

3. Tulgar M. Fundamental scientific factors in electrical stimulation of the nervous system. Clin Neurophysiol. 1995;12:230-6.

4. Ranck JB. Which elements are excited in electrical stimulation of mammalian central nervous system: a review. Brain Res. 1975;98:417-40.

5. Andersson SA. Pain control by sensory stimulation. In: Bonica JJ, Liebeskind JC, editors. Pain Research and Therapy. Raven Press, New York. 1979;3:569-85.

6. Eriksson MBE, Sjolund BH, Nielsen S. Long term results of peripheral conditioning stimulation as an analgesic measure in chronic pain. Pain. 1979;6: 335-47.

7. Johnson MI, Ashton CH, Bousfield DR, Thompson JW. Analgesic effects of different frequencies of transcutaneous electrical nerve stimulation on cold-induced pain in normal subjects. Pain. 1989;39:231-6.

8. Johnson MI, Ashton CH, Thompson JW. An indepth study of long-term users of transcutaneous electrical nerve stimulation (TENS). Pain. 1991;44: 221-9.

9. Tulgar M, McGlone F, Bowsher D, Miles JB. Comparative effectiveness of different stimulation modes in relieving pain. Part I. A pilot study. Pain. 1991;47:151-5.

10. Tulgar M, McGlone F, Bowsher D, Miles JB. Comparative effectiveness of different stimulation modes in relieving pain. Part II. A double-blind controlled long-term clinical trial. Pain. 1991;47: 157-62.
11. Tulgar M. Advances in electrical nerve stimulation techniques to manage chronic pain: an overview. Adv Ther. 1992;9:366-72.

12. Tulgar M, Tulgar O, Herken H. Psychophysical responses to experimentally induced heat and cold pain before, during and after transcutaneous electrical nerve stimulation. Neuromodulation. 2003;6:229-36.

13. Tulgar M, Barolat G, Ketcik B. Analysis of paremeters for epidural spinal cord stimulation. Part I. Perception and tolerance thresholds resulting from 1100 combinations. Stereotact Funct Neurosurg. 1993;61:129-39.

14. Tulgar M, Barolat G, Ketcik B. Analysis of parameters for epidural spinal cord stimulation. Part II. Usage ranges resulting from 3000 combinations. Stereotact Funct Neurosurg. 1993;61:140-5.

15. Tulgar M, Barolat G, Ketcik B. Analysis of parameters for epidural spinal cord stimulation. Part III. Topographical distribution of parasthesiae resulting from 266 combinations with contacts implanted in the mid-cervical and low-thoracic vertebral levels. Stereotact Funct Neurosurg. 1993;61: 146-55.

16. Tulgar M, Soysal OM. Inductively coupled transmission of neuro-active signals: analysis of optimal parameters. Med Phys. 2003;30:79-87.

17. Kalkan E, Arican M, Kalkan SS, et al. A new neuroimplantable device: the Tulgar implant. Initial results of animal testing. Neuromodulation. 2005;4:249-56.

18. Tulgar M, Ozyurt ME. New generation neuroimplants. Paper presented at International Neuroimplantation Congress; 22-23 January, Istanbul, Turkey; 2010.

19. Wikibook Contributors. Human Physiology. Available at: http://upload.wikimedia.org/wiki media/en-labs/c/cd/Human_Physiology.pdf. Accessed Apr 17, 2012.

20. Omura Y. Basic electrical parameters for safe and effective electro-therapeutics (electro-acupuncture, TES, TENMS (or TEMS), TENS and electro-magnetic field stimulation with or without drug field) for pain, neuromuscular skeletal problems, and circulatory disturbances. Acupunct Electrother Res. 1987;12:201-25.

21. Schachter SC, Saper CB. Vagus nerve stimulation. Epilepsia. 1988;39:677-86.

22. Guberman A. Vagus nerve stimulation in the treatment of epilepsy: analysis. Neurology. 2004;171:1165-6. 
23. Melzack R, Wall PD. On the nature of cutaneous sensory mechanisms. Brain. 1962;85:331-56.

24. Melzack R, Wall PD. Pain mechanisms. A new theory. Science. 1965;150:971-9.

25. Scheibel ME, Scheibel AB. The response of reticular units to repetitive stimuli. Arch Ital Biol. 1965; 103:279-99.
26. Malhan S, Oksuz E, Bozkurt R, et al. Cost utility analysis of vagal nerve stimulators (VNS) versus medical treatments for refractory epilepsy in Turkey. Presented by executives of the Turkish Social Security Institution (SGK) at the European Health Authorities Meeting; Geneva, Switzerland; 2010. 